\title{
Does Survey Respondents' Immigrant Background Affect the Measurement and Prediction of Immigration Attitudes? An Illustration in Two Steps
}

\section{Oriane Sarrasin ${ }^{\mathrm{I}}$, Eva G. T. Green ${ }^{\mathrm{I}}$, Nicole Fasel $^{\mathrm{I}}$ and Eldad Davidov ${ }^{2}$}

\author{
${ }^{\mathrm{I}}$ Faculty of Social and Political Sciences, University of Lausanne, CH-ıо 5 Lausanne and \\ ${ }^{2}$ Institute of Sociology, University of Zurich, CH-8050 Zurich, Switzerland
}

Over the past few decades, Western societies have become highly diverse, with an increasing share of the population having foreign roots. Just like the native population, defined here as national citizens with national ancestry and no foreign roots (up to the third generation), individuals with an immigrant background have opinions on newcomers to the country. Yet, most research on attitudes toward immigration using large-scale survey data routinely excludes their responses, without verifying whether their inclusion actually affects the findings. We argue here that it is crucial to examine whether methodological considerations actually justify exclusion. To illustrate how to do so, we define two necessary steps for evaluating the impact of respondents' immigrant background and apply them to data from a Swiss survey.

\section{Immigration Attitudes and Sample Selection}

Most large-scale research on immigration attitudes relies on secondary data from international social surveys. In these surveys, respondents are generally invited to provide an evaluative judgment of immigrants or immigration in general (e.g., "The government spends too much money assisting immigrants"; International Social Survey Programme, 2003) or to immigrants from regions with different economic conditions (e.g., "people from the poorer countries in Europe"; European Social Survey, 2002). Because no specific group is mentioned, it is often argued that respondents with an immigrant background could have their own national

All correspondence concerning this article should be addressed to Oriane Sarrasin, Faculty of Social and Political Sciences, University of Lausanne, Geopolis, CH1015 Lausanne, Switzerland. E-mail: oriane.sarrasin@gmail.com. 
group in mind when answering such questions, which would presumably lead them to adopt more positive attitudes (Hjerm, 2009). It has also been suggested that the reasons for adopting negative immigration attitudes differ as a function of immigrant background (Herda, 2010).

Consequently, responses from respondents with an immigrant background are often excluded. To do so, various criteria have been used, such as not having the citizenship of the host country (e.g, Green, Sarrasin, Fasel, \& Staerklé, 20г I) and being born outside the country (e.g., Mayda, 2006). Less frequently, some studies have included all respondents in the analyses, and immigrant background was used as a control variable (e.g., foreign born, Hainmueller \& Hiscox, 2007; second-generation immigrants, Hjerm, 2009). Despite these precautions, little is known as to whether the inclusion of respondents with an immigrant background actually affects immigration attitudes and their prediction. To fill this gap, the present study illustrates how to evaluate, in two steps, whether methodological requirements for inclusion are fulfilled.

\section{Step 1: Testing for the Invariance of Measurement}

When using data from distinct groups, researchers should always ensure that the differences (or the absence of differences) in scores reflect "true" differences in the concepts underlying the items and are not biased by methodological artifacts (e.g., inappropriate translation; Heath, Martin, \& Spreckelsen, 2009). Before cross-group comparisons or pooling the data of the different groups, they are advised to verify, most often using multigroup confirmatory factor analysis (MGCFA), whether the measurement of the concepts of interest is invariant across the groups under consideration (Steenkamp \& Baumgartner, I998). Measurement invariance methods have been applied to test the similarity of a broad array of concepts, such as immigration attitudes (e.g., Davidov, Meuleman, Billiet, \& Schmidt, 2008; Sarrasin, Green, Berchtold, \& Davidov, 20I3). In contrast, whether the respondents' immigrant background affects the invariance of social and political attitudes has hardly received empirical attention (for an exception see Kankaras \& Moors, 20I2). Furthermore, to our knowledge, the current study is the first to test whether the measurement of immigration attitudes differed between natives and individuals with an immigrant background.

To examine this, we will rely on a series of hierarchical and increasingly stricter tests. Configural invariance (Horn, McArdle, \& Mason, I983) - the least strict levelrequires a similar number of factors and a similar pattern of salient and nonsalient item loadings across groups. The second level, metric invariance, examines whether items in one group behave similarly in the other group(s) (Selig, Card, \& Little, 2008). This is done by constraining the item loadings to equality across groups. Because metric invariance relies on covariations between items, it is possible, at this level, to test whether concepts relate to each other in a similar way across groups (Brown, 2006; Van de Vijver \& Leung, I997). A meaningful comparison of factor latent means across groups requires an even stricter level of invariance-scalar invariance-in which item intercepts are additionally constrained to equality. Finally, note that because of their strictness, full metric or scalar invariant models are hard to achieve (Steenkamp \& Baumgartner, I998). If a few parameters (loadings or 
intercepts) are noninvariant, researchers have the possibility to rely on partially invariant scores. ${ }^{1}$ At least two items per factor should be invariant to allow a comparison of the constructs across the groups or the data to be pooled (Byrne, Shavelson, \& Muthén, I989).

\section{Step 2: Testing for Differences in Means and Relationships}

Although invariance testing is mostly used to ensure that measurement issues do not bias analyses performed in later stages, researchers can also rely on multigroup analyses to test for group differences in structural parameters such as means or relationships between concepts once scalar or metric invariance (partial or full) has been established. Thus, in this second step, we examine first whether the means of immigration attitudes differ between natives and individuals with an immigrant background. Then, akin to exploring nomological validity as defined by Cronbach and Meehl (I955), we test whether the relationship between nationalism and immigration attitudes varies across these groups.

Individuals with an immigrant background are generally found to express more positive stances toward immigration than natives (e.g., Hjerm, 2009). Furthermore, the higher the integration of immigrants, the closer their attitudes toward immigration are to those of natives (Valentova \& Berzosa, 20I2). In a similar vein, longer-established immigrants from neighboring culturally close countries resemble native citizens in their political attitudes, whereas the attitudes of immigrants from more distant countries are similar to those of their fellow citizens living in their home country (Kankaras \& Moors, 20I2). Based on these results, we expect individuals with an immigrant background, and especially recent immigrants from distant countries, to be more positive toward immigration than natives (HI). However, such possible differences should not prevent researchers from pooling the data as long as they display sufficient levels of invariance and immigrant background is accounted for in the model.

In contrast, when differences (in the strength and/or direction) of the operating mechanisms underlying the formation of immigration attitudes occur, the inclusion of individuals with an immigrant background requires more thorough theoretical and empirical consideration. Researchers have two alternatives. They may focus on one group (e.g., natives) and discard responses from the other groups (e.g., individuals with an immigrant background). Alternatively, they may theoretically and empirically consider both groups, while including the variable differentiating the two groups (e.g., immigrant background) as a moderator in their models.

To illustrate this point, we examine how a blind and uncritical attachment to the nation (or nationalism) relates to immigration attitudes among natives and individuals with an immigrant background. Among natives, nationalism is generally related to negative immigration attitudes (e.g., Blank \& Schmidt, 2003). Among individuals with an immigrant background, a blind attachment may reflect a strong desire to belong to

\footnotetext{
${ }^{1}$ Note that the use of partially invariant scores has been contested on the ground that they may deliver biased comparisons of latent means or relationships between concepts (De Beuckelaer \& Swinnen, 20II; Steinmetz, 20ı I; Van de Vijver \& Leung, I997).
} 
the receiving country. Because of that, if negative attitudes toward immigrants are widespread among natives, they may be "transferred to immigrant groups who are seeking acceptance from the majority group" (Verkuyten \& Martinovic, 20I2, p. 99). This should be stronger among longer-established immigrants from neighboring countries, as they are more likely to be influenced by the values of the receiving country (Schiefer, 20I3). Thus, we expect that among both natives and individuals with an immigration background, and especially those that are longer established, nationalism relates to anti-immigration attitudes $\left(\mathrm{H}_{2}\right)$.

\section{The Current Study}

The present study uses data from Switzerland to illustrate how to evaluate whether excluding the opinions of individuals with an immigrant background is justifiable. More than $30 \%$ of the population in Switzerland has foreign roots (Swiss Federal Statistical Office, 20I2a). The largest immigrant groups (i.e., individuals who do not possess Swiss citizenship) are former Yugoslavs (all countries considered together; $20.2 \%$ of the immigrant population), Italians ( $\mathrm{I}_{5} .6 \%$ ), Germans ( $5.2 \%$ ), and Portuguese (I2.7\%; Swiss Federal Statistical Office, 20г2b). In such a context, it is crucial to examine whether respondents with an immigrant background can be included in the analysis, as their exclusion with no further consideration would lead to disregarding the opinion of a considerable share of the society.

We analyzed data from the Swiss survey "Monitoring Misanthropy and Rightwing Extremist Attitudes 2005" (hereafter, Monitoring; Cattacin, Gerber, Sardi, \& Wegener, 2006) from the German-speaking part of Switzerland. ${ }^{2}$ In this survey, the two largest immigrant groups living in Switzerland were oversampled: While Italians represent a longer-established immigrant group, former Yugoslavs represent recent immigrants who are generally perceived by the Swiss native population as culturally more distant (Wimmer, 2004). Thus, these data enabled us to perform more finegrained comparisons instead of assessing the impact of having a generic immigrant background. ${ }^{3}$

\footnotetext{
${ }^{2}$ We did not include data from the three Swiss linguistic minorities (French, Italian, Rumantsch). Studying the interaction between living in a majority versus minority region and having immigrant background could be of interest, particularly in Switzerland where both nationalism and immigration attitudes vary greatly across regions (e.g., Green et al., 20II). However, for the sake of simplicity and to avoid confounding effects (i.e., the use of different languages is known to bias measurement invariance; Davidov \& De Beuckelaer, 20Iо; in Switzerland, Sarrasin et al., 20I3), we restrained our analysis to the Germanspeaking region.

${ }^{3}$ Individuals of $\mathrm{I} 2$ other (not oversampled) nationalities took part in the Monitoring 2005, with an average number of 20 respondents per nationality (ranging from I Sri Lankan to 65 French; in addition, 72 respondents are classified in "others"). Although none of these groups is large enough to perform reliable MGCFA, the grouping of all respondents with an immigrant background would have been possible. However, to provide a clear and more detailed illustration, we restricted our analyses to Italian and former Yugoslav respondents. For readers interested in pooling different immigrant groups, analyses performed on another survey are available on request.
} 


\section{Method}

\section{Respondents}

Among the respondents $(N=\mathrm{I}, 099)$, we distinguished between three groups: Natives (born in Switzerland, parents and grandparents born in Switzerland, no dual citizenship; $N=720$ ), Italians $(N=\mathrm{I} 48)$, and former Yugoslavs (from Serbia, Kosovo, Croatia, the Former Republic of Macedonia, and Bosnia; $N=23 \mathrm{I}$ ). For the two groups with an immigrant background, we included respondents who not only had the citizenship of the country of origin but whose parents and grandparents also did. In the resulting subsamples, the majority of respondents were born abroad (Italians: 62.I6\%; former Yugoslavs: 89.6r\%), and only few possessed Swiss citizenship in addition to their primary citizenship (Italians: I2.16\%; former Yugoslavs: $3.03 \%) .{ }^{4}$

Both Italian $\left(M_{\text {age }}=39 . \mathrm{II}, S D=\mathrm{I} 4.69 ; t(866)=7.83, p<.00 \mathrm{I}\right)$ and former Yugoslav $\left(M_{\text {age }}=28.33, S D=\mathrm{II} .02 ; t(949)=\mathrm{I} 8.87, \quad p<.00 \mathrm{I}\right)$ respondents were younger than natives $\left(M_{\mathrm{age}}=50.89, S D=\mathrm{I} 7.06\right)$. In addition, there was a greater percentage of men in the Italian (5I.35\%) and former Yugoslav $(52.38 \%)$ samples than in the native sample $\left(42.08 \% ; \chi^{2}(2)=9.84, p=.007\right)$. Finally, a greater proportion of natives $(36.8 \mathrm{I} \%)$ reported having at least a high school diploma compared with Italian $(\mathrm{I} 8.92 \%)$ and former Yugoslav respondents $\left(\mathrm{I} 4.72 \% ; \chi^{2}(2)=50.43, p<.00 \mathrm{I}\right)$.

\section{Measures}

Six items were selected to tap the concept of immigration attitudes (please note that although they address various and debated aspects of immigration, they cannot represent all items usually used to measure immigration attitudes in surveys). In addition, one item was used to measure nationalism (for exact item wording, see Appendix). In all cases, respondents indicated their opinion on scales ranging from I (totally agree) to 4 (totally disagree), and scores were reversed so that higher scores would indicate more negative immigration attitudes or a blind attachment to Switzerland. Means, standard deviations, and correlations between all items are displayed in Table I.

\section{Results}

\section{Strategy of Analysis}

The invariance of the measurement and structure was examined using MGCFAs and multigroup structural equation modeling (MGSEM: Bollen, I989; Jöreskog, I97I). All analyses were performed with Mplus 5.I (Muthén \& Muthén, 2008). Confirmatory factor analysis and structural equation modeling models are usually considered to fit the data adequately when the comparative fit index (CFI) is $>.95$ and the root mean square error of approximation (RMSEA) is $<.06$ (Hu \& Bentler, 1999), although values between .05 and .08 are usually considered acceptable

\footnotetext{
${ }^{4}$ Additional analyses excluding Italian $(N=\mathrm{I} 8)$ and former Yugoslav $(N=7)$ immigrants who possess Swiss citizenship revealed similar findings (with one exception: Swiss natives' immigration attitudes were not significantly more negative than Italians' attitudes; Model I e-Model Ii, $\Delta \chi_{2}, p=.228$ ).
} 
Table I

Means, Standard Deviations, and Correlations for Immigration Attitudes and National Attachment Items by Group

\begin{tabular}{|c|c|c|c|c|c|c|c|}
\hline $\begin{array}{l}\text { Groups } \\
\text { Items }\end{array}$ & $\mathrm{M}(\mathrm{SD})$ & $\begin{array}{l}\text { Social } \\
\text { benefits }\end{array}$ & Security & Unemployment & School & Limits & Environment \\
\hline \multicolumn{8}{|l|}{ Natives } \\
\hline Social benefits & $2.9(0.89)$ & & & & & & \\
\hline Security & 2.12 (I.OI) & $0.42^{* * * *}$ & & & & & \\
\hline Unemployment & 2.56 (I.OI) & $0.44^{* * * *}$ & $0.37^{* * * * *}$ & & & & \\
\hline School & $2.70(\mathrm{I} .00)$ & $0.46^{* * * *}$ & $0.40^{* * * *}$ & $0.4 \mathrm{I}^{* * * *}$ & & & \\
\hline Limits & $3.05(0.97)$ & $0.59^{* * * *}$ & $0.38^{* * * *}$ & $0.44^{* * * *}$ & $0.47^{* * * *}$ & & \\
\hline Environment & $2.29(0.94)$ & $0.44^{* * * *}$ & $0.4 \mathrm{I}^{* * * *}$ & $0.30^{* * * *}$ & $0.43^{* * *}$ & $0.40^{* * * *}$ & \\
\hline Citizen & $3.40(0.88)$ & $0.28^{* * * * *}$ & $0.24^{* * * * *}$ & o. I9 $9^{* * * *}$ & 0.20 **** & $0.26^{* * * *}$ & 0.23 **** \\
\hline \multicolumn{8}{|l|}{ Italians } \\
\hline Social benefits & 2.6I (0.97) & & & & & & \\
\hline Security & 2.I I (I.02) & $0.38^{* * * *}$ & & & & & \\
\hline Unemployment & $2.45(\mathrm{I} .03)$ & $0.40^{\text {****** }}$ & $0.43^{* * * *}$ & & & & \\
\hline School & 2.I5 (0.99) & $0.25^{* *}$ & $0.2 \mathrm{I}^{*}$ & $0.22 *$ & & & \\
\hline Limits & $2.85(\mathrm{I} .02)$ & $0.49^{* * * *}$ & $0.45^{* * * *}$ & $0.36^{* * * *}$ & O.I4 & & \\
\hline Environment & $2.10(0.95)$ & $0.37^{* * * *}$ & $0.32^{\text {**** }}$ & $0.30^{* * * *}$ & $0.29^{* * * *}$ & $0.32^{* * * *}$ & \\
\hline Citizen & 2.43 (1.00) & 0.02 & 0.13 & 0.00 & 0.13 & 0.08 & $0.28^{* *}$ \\
\hline \multicolumn{8}{|l|}{ Former Yugoslavs } \\
\hline Social benefits & $2.20(\mathrm{I} .00)$ & & & & & & \\
\hline Security & I. 68 (0.9I) & $0.35^{* * * *}$ & & & & & \\
\hline Unemployment & $2.19(0.96)$ & $0.26^{* * * * *}$ & $0.32^{\text {****** }}$ & & & & \\
\hline School & I. $65(0.92)$ & $0.26^{* * * * *}$ & $0.40^{* * * *}$ & $0.25^{* * * *}$ & & & \\
\hline Limits & 2.40 (I.08) & $0.29^{\text {****** }}$ & $0.39^{* * * *}$ & $0.34^{* * * *}$ & $0.22^{* * *}$ & & \\
\hline Environment & I. $89(0.92)$ & $0.42^{* * * *}$ & $0.33^{* * * *}$ & $0.3 \mathrm{I}^{* * * *}$ & $0.23^{* * * *}$ & $0.22^{* *}$ & \\
\hline Citizen & 2.73 (I.I2) & $-0.0 \mathrm{I}$ & o.I3\# & -0.04 & 0.06 & $0.24^{* * * * *}$ & 0.05 \\
\hline
\end{tabular}

Note. ${ }^{* * * *} p<.00 \mathrm{I},{ }^{*} p<<.0 \mathrm{I},{ }^{*} p<.05, \# p<$. I0.

(Schermelleh-Engel, Moosbrugger, \& Müller, 2003). The chi-square and the other fit indices for each model are presented in Table 2.

These indices provide information on whether the model fits the data well, but not whether a stricter level of invariance is reached. To do so, it is advisable to rely on both a nonsignificant chi-square difference test ${ }^{5}$ and on small changes in other fit indices. Regarding the latter, we followed recommendations by Chen (2007), who proposed that a decrease up to .oro in CFI coupled with an increase up to .oI 5 in RMSEA indicates that a stricter level of invariance is reached. Changes exceeding

\footnotetext{
${ }^{5}$ Because chi-square values are sensitive to large sample sizes (Meade \& Lautenschlager, 2004), some authors recommend to not to rely on the chi-square difference test (Cheung \& Rensvold, 2002). However, the smallest sample in our study (e.g., $N=\mathrm{I} 48$ ) hardly qualifies as large (Kline, 20I I). Moreover, if changes in fit indices were acceptable but the chi-square difference was significant, we followed Brown's (2006) recommendations and carefully examined whether the increase in chi-square was mostly due to one parameter, which strongly differed across groups, or rather due to several negligible differences. If the former was the case, we relaxed the equality constraint of that parameter.
} 
Table 2

Chi-Square Value and Fit Indices (CFI and RMSEA) of All Models

\begin{tabular}{|c|c|c|c|c|}
\hline Model & $d f$ & chi-square & CFI & RMS \\
\hline \multicolumn{5}{|l|}{ Immigration attitudes (six items) } \\
\hline Ia Configural & 27 & $54.6 \mathrm{I}, p=.00 \mathrm{I}$ & $.98 \mathrm{I}$ & .053 \\
\hline Ib Full metric & 37 & $68.93, p=.00 \mathrm{I}$ & .978 & .049 \\
\hline Ic Full scalar & 47 & $\mathrm{I} 48 . \mathrm{I} 6, p<. \mathrm{OOI}$ & $.93 \mathrm{I}$ & .077 \\
\hline Id Partial scalar I (school item) & 45 & $90.24, p<.00 \mathrm{I}$ & .969 & .052 \\
\hline Ie Partial scalar 2 (school and social benefits items) & 44 & $78.6 \mathrm{I}, p<.00 \mathrm{I}$ & .977 & .046 \\
\hline If Latent means & 46 & $\mathrm{I} 53.2 \mathrm{I}, p<.00 \mathrm{I}$ & .927 & .080 \\
\hline Ig Latent means, Swiss mean $=$ free & 45 & $\mathrm{I} 00.22, p<.00 \mathrm{I}$ & .963 & .058 \\
\hline Ih Latent means, Italian mean $=$ free & 45 & $\mathrm{I} 53.2 \mathrm{I}, p<.00 \mathrm{I}$ & .927 & $.08 \mathrm{I}$ \\
\hline ii Latent means, former Yugoslav mean $=$ free & 45 & $82.96, p<$. oо I & .974 & .048 \\
\hline \multicolumn{5}{|l|}{ Immigration attitudes (six items) and nationalism (one item) } \\
\hline 2a Full metric & $5^{2}$ & $96.76, p<.00 \mathrm{I}$ & $.97 \mathrm{I}$ & .049 \\
\hline $2 \mathrm{~b}$ Full metric and relationship & 54 & II $3 . \mathrm{I} 7, p<$.OOI & .962 & .055 \\
\hline 2c Full metric and relationship, Swiss $=$ free & 53 & $96.94, p<.00 \mathrm{I}$ & .972 & .048 \\
\hline $2 \mathrm{~d}$ Full metric and relationship, Italian $=$ free & 53 & III.I $2, p<$. OOI & .963 & .055 \\
\hline 2e Full metric and relationship, former Yugoslav $=$ free & 53 & I02.06, $p<.00 \mathrm{I}$ & .969 & .050 \\
\hline
\end{tabular}

these recommended cutoff values indicate that one or several parameters differ across the groups. To identify these parameters and allow them to vary across groups, we examined the modification indices (MIs), which indicate the parameters that contribute to the largest increase in chi-square.

\section{Step 1: Invariance of Measurement}

We first examined whether the measurement of immigration attitudes was invariant across natives and the two groups with an immigrant background. We tested for configural, metric, and scalar invariance. Although two noninvariant items are sufficient to consider partial invariance, we examined, in addition, whether specific noninvariant parameters affected the comparison of latent means or relationships between concepts (as performed in Step 2). In other words, we verified whether the means and relationships between nationalism and immigration attitudes ranked in the same order across the groups (e.g., most negative attitudes among natives) in both the full invariant and the partial invariant models (see Chen, 2008). If the cross-group rank order differed, the noninvariant items were discarded.

The model testing for the configural invariance of the six immigration attitude items had an acceptable fit to the data (Model ra). A nonsignificant chi-square difference test $\left(p=. \mathrm{I}_{59}\right)$ and small changes in fit indices indicate that metric invariance (Model Ib) was reached. In contrast, a sharp increase in the chi-square value $(p<.00 \mathrm{I})$ and large changes in fit indices indicated that full scalar invariance (Model Ic) was not reached. One MI-related to the intercept of the School item-was considerably larger than the others. Thus, we released the cross-group 
equality constraint on this factor intercept in the Italian and former Yugoslav groups. The resulting partial scalar model (Model Id) was, however, still significantly different from the full metric model $\left(\Delta \chi^{2}, p=.006\right)$. MIs further indicated that the intercept of the Social benefits item, similar in the Italian and former Yugoslav groups, differed considerably from the native group. Thus, our second partial scalar invariance model (Model Ie) allowed this intercept to vary between the immigrant background and the native groups. This model was supported by the data $\left(\Delta \chi^{2}, p=.207\right)$. Additional analyses (not presented here) revealed that the rank order of latent means is similar in the full scalar model and Model re. We thus retained these two items for Step 2 analyses.

\section{Step 2: Invariance of Structural Parameters}

In the second step, we compared the latent means of immigration attitudes and the impact of nationalism on these attitudes across natives and respondents from the two immigrant background groups. We followed the recommended procedure in the literature, which suggests testing mean differences on a full or partial scalar invariant model (e.g., Steenkamp \& Baumgartner, I998) and constraining the latent means to be equal across the groups. Latent means were considered invariant if the differences between the partial scalar invariance model (Model re) and the model that additionally included a cross-group equality constraint on the latent means fell within the recommended criteria (Model If). Results indicated that this was not the case $\left(\Delta \chi^{2}\right.$, $p<$.oor). Next, we tested three different models, each of which constrained the latent variable to equality across a different pair of samples, while allowing the mean to vary in the third sample. All three models were rejected (Model ig: $\Delta \chi^{2}$, $p<$. oor; Model Ih: $\Delta \chi^{2}, p<.00$ I; Model ıi: $\left.\Delta \chi^{2}, p=.037\right)$ : The means could not be considered invariant between any of the groups. Confirming $\mathrm{HI}_{\mathrm{I}}$, Swiss natives expressed the most negative attitudes toward immigration $(\kappa=2 . \mathrm{I} 4)$, followed by the Italian group $(\kappa=2.0 \mathrm{I})$, with the former Yugoslav group displaying the lowest scores $(\kappa=\mathrm{I} .68)$.

To examine whether the direct impact of nationalism on attitudes toward immigration attitudes was similar across groups, the nationalism item was added to the metric invariance model (Model 2a). We then constrained its impact to be equal across groups (Model 2b) and again compared the fit of the two models. A significant chi-square difference $(p<$. oor $)$ indicated that the impact of nationalism differed across the groups. Next, we tested three consecutive models where this relationship was constrained to equality in two samples but was freely estimated in the third sample. The model (2c) constraining the relationship to be equal in the two immigrant background groups did not differ significantly from Model $2 \mathrm{a}$ $(p=.67 \mathrm{I})$. In contrast, the models constraining the relationship to be equal between the Swiss and former Yugoslav groups (Model 2d; $p<.00 \mathrm{I}$ ) and between the Swiss and Italian groups (Model 2e; $p=.02 \mathrm{I}$ ) were significantly worse. In line with our prediction $\left(\mathrm{H}_{2}\right)$, nationalism was related to negative immigration attitudes in all groups. However, its impact was stronger in the Swiss group $(b=0.27, S E=0.03, p<.00 \mathrm{I})$ than in the two other groups $(b=0.08, S E=0.04$, $p=.022)$. 


\section{Controls}

Finally, we examined whether similar conclusions were reached when controlling for gender, age, and education (dummy variable, $\mathrm{I}=$ high school diploma). When sociodemographic information was controlled for, both the immigration attitudes' latent means $(p=.374)$ and the relationship between nationalism and immigration attitudes $(p=.279)$ did not significantly differ between Swiss natives and Italian respondents. In contrast, the differences between natives and former Yugoslav respondents remained significant.

\section{Discussion}

Most research on immigration attitudes using large-scale survey data routinely excludes respondents with an immigrant background without first testing whether this decision is empirically justified. In the present study, we argued that these respondents can be included, provided that they do not substantially affect the measurement and prediction of immigration attitudes. With this aim in mind, we outlined and illustrated, with Swiss data, a two-step analytic strategy. We found that, in the present case, the measurement of immigration attitudes was sufficiently invariant to include respondents with an immigrant background. In contrast, slight differences in latent means and predictions of immigration attitudes need to be discussed to determine whether they call for excluding these respondents.

\section{How to Deal with Differences in Means and Relationships across Groups}

Confirming our expectations and in line with prior research, respondents with an immigrant background expressed more positive immigration attitudes than natives (HI), and nationalism was related to negative immigration attitudes in all groups (H2), albeit more strongly among the natives. This may indicate that in the present case, despite differences in levels of attitudes, similar mechanisms (e.g., the willingness to protect the nation/host country from outsiders) underlie negative reactions to immigrants across both native and immigrant groups. These results cannot, however, be generalized to all receiving countries, all groups of immigrants, or all immigration attitude scales. Instead, we recommend to researchers who wish to include respondents with an immigrant background to follow the two-step procedure described in the present study. If they were to find similar patterns among groups, as in the present case, including respondents with an immigrant background in further analyses is warranted. Moreover, to adequately account for slight differences in means and predictions, "immigrant background" should also be used as a moderating variable. For instance, in regression analyses, not only nationalism but also immigrant background and the interaction between the two should be used as predictors. In contrast, if the procedure described in this study were to reveal strong variations in the relationships between attitudes and other theoretical constructs of interest (e.g., a positive relationship in one group and a negative in the other), in addition to controlling for the 
immigrant background of the respondent, one could consider substantive explanations for such differences.

\section{How to Define Immigrant Background}

In line with past research, we found more pronounced differences between natives and recent immigrant groups than between natives and longer-established immigrants. Moreover, these latter differences disappeared when sociodemographic factors were controlled for, indicating that the immigrant background as such may not have caused these differences in the first place. This underlines the importance of considering more fine-grained subcategorizations instead of a broad "immigrant background" category. However, this may not be possible with data from most large-scale surveys, as immigrant groups are rarely oversampled, despite immigrants, and especially those from distant countries, being often both underrepresented and misrepresented (Lagana, Elcheroth, Penic, Kleiner, \& Fasel, 20I3). Researchers should thus deliberate not only on the "broadness" of the general "immigrant background" category in the data they are analyzing but, when subdividing it into specific immigrant groups, also inquire whether the respondents accurately represent the migrant population of the host country.

\section{Conclusion}

To sum up, we presented a two-step procedure on how to verify whether the inclusion of individuals with an immigrant background affects the measurement and prediction of immigration attitudes. Although the conclusions drawn from the present example cannot be generalized to the entire body of research on immigration attitudes, they provide empirical guidance on (I) how to examine whether immigrant background affects the measurement and prediction of immigration attitudes and (2) how researchers can try to avoid such potential bias without drastically reducing the sample size. When studying a highly salient societal phenomenon such as immigration, it is crucial to try to include all members of society and to avoid a priori unjustified exclusion.

\section{Supplementary Data}

Supplementary data are available at IfPOR online.

\section{Acknowledgments}

The fourth author thanks the URPP program 'Social Networks', University of Zurich.

\section{References}

Blank, T., \& Schmidt, P. (2003). National identity in a united Germany: Nationalism or patriotism? An empirical test with representative data. Political Psychology, 24, 289-3 I2. doi: Io. I I I / o r 62-895X.00329. 
Bollen, K.A. (1989). Structural equations with latent variables. New York, NY: Wiley.

Brown, T.A. (2006). Confirmatory factor analysis for applied research. New York, NY: Guilford Press.

Byrne, B.M., Shavelson, R.J., \& Muthen, B. (I989). Testing for the equivalence of factor covariance and mean structures: The issues of partial measurement invariance. Psychological Bulletin, I05, 456-466. doi:Io.1037/0033-2909.105·3.456.

Cattacin, S., Gerber, B., Sardi, M., \& Wegener, R. (2006). Monitoring rightming extremist attitudes, xenophobia and misanthropy in Smitzerland. An explorative study. Research report-PNR 40+, Sociograph-Sociological Research. Geneva: University of Geneva.

Chen, F.F. (2007). Sensitivity of goodness of fit indexes to lack of measurement invariance. Structural Equation Modeling, I4, 464-504. doi:Io.Io8o/ I07055 I0701301834.

Chen, F.F. (2008). What happens if we compare chopsticks with forks? The impact of making inappropriate comparisons in cross-cultural research. Fournal of Personality and Social Psychology, 95, гоo5-гог 8. doi:ıо.го37/aoor3193.

Cheung, G.W., \& Rensvold, R.B. (2002). Evaluating goodness-of-fit indexes for testing measurement invariance. Structural Equation Modeling, 9, 233-255. doi:1o.1207/ Si 5328007SEMogo2_5.

Cronbach, L.J., \& Meehl, P.E. (I955). Construct validity in psychological tests. Psychological Bulletin, 52, 28I-302. doi:I0.1037/hoo40957.

Davidov, E., \& De Beuckelaer, A. (2010). How harmful are survey translations? A test with Schwartz's human values instrument. International fournal of Public Opinion Research, 22, 485-510. doi:Iо.г093/ijpor/edqo3o.

Davidov, E., Meuleman, B., Billiet, J., \& Schmidt, P. (2008). Values and support for immigration: A cross-country comparison. European Sociological Reviem, 24, 583-599. doi:Io. I093/esr/jcno2o.

De Beuckelaer, A., \& Swinnen, G. (20II). Biased latent variable mean comparisons due to measurement noninvariance: A simulation study. In E. Davidov, P. Schmidt \& J. Billiet (Eds.), Cross-cultural analysis: Methods and applications (pp. II7-I47). New York, NY: Routledge.

European Social Survey. (2002). ESS Round I: European Social Survey Round I Data (2002). Data file edition 6.2. Norwegian Social Science Data Services, Norway-Data Archive and distributor of ESS data.

Green, E.G. T., Sarrasin, O., Fasel, N., \& Staerklé, C. (201 I). Nationalism and patriotism as predictors of immigration attitudes in Switzerland: A municipalitylevel analysis. Smiss Political Science Reviem, I7, 369-393. doi:Io.ıIII/j.I6626370.201 I.02030.x.

Hainmueller, J., \& Hiscox, M.J. (2007). Educated preferences: Explaining attitudes toward immigration in Europe. International Organization, 6I, 399-442. doi:Io.IoI7/Soo20818307070I42.

Heath, A., Martin, J., \& Spreckelsen, T. (2009). Cross-national comparability of survey attitude measures. International Journal of Public Opinion Research, 2I, 293-3I5. doi:Io. I093/ijpor/edpo34.

Herda, D. (2010). How many immigrants? Foreign-born population innumeracy in Europe. Public Opinion Quarterly, 74, 674-695. doi:Io.1093/poq/nfqoi3. 
Hjerm, M. (2009). Anti-immigrant attitudes and cross-municipal variation in the proportion of immigrants. Acta Sociologica, 52, 47-62. doi:Io.II77/ ооог6993о8гоо633.

Horn, J.L., McArdle, J.J., \& Mason, R. (I983). When is invariance not invariant: A practical scientist's look at the ethereal concept of factor invariance. Southern Psychologist, I7, I79-188.

Hu, L.-T., \& Bentler, P.M. (I999). Cutoff criteria for fix indexes in covariance structure analysis: Conventional criteria versus new alternatives. Structural Equation Modeling, 6, I-55. doi:ı.1080/г07055 I9909540г I8.

International Social Survey Programme. (2003). National Identity II, ZA 3910 [codebook]. Cologne, Germany: GESIS.

Jöreskog, K.G. (I97I). Simultaneous factor analysis in several populations. Psychometrika, 36, 409-426. doi: го.1007/BFo2291366.

Kline, R.B. (20 I ). Principles and practice of structural equation modeling (3rd ed.). New York, NY: The Guilford Press.

Kankaras, M., \& Moors, G. (2012). Cross-national and cross-ethnic differences in attitudes: A case of Luxembourg. Cross-Cultural Research, 46, 224-254. doi: I o. I I 77/ I 069397 I I 2440945.

Lagana, F., Elcheroth, G., Penic, S., Kleiner, B., \& Fasel, N. (2013). National minorities and their representation in social surveys: Which practices make a difference? Quality and Quantity, 47, I287-I3I4. doi:Io.I007/s I I 35-0I I-959I-I.

Mayda, A.M. (2006). Who is against immigration? A cross-country investigation of individual attitudes toward immigrants. The Reviem of Economics and Statistics, 88, 5 I0-530. doi: Io. I $62 /$ rest.88.3.5 Io.

Meade, A.W., \& Lautenschlager, G.J. (2004). A Monte-Carlo study of confirmatory factor analytic tests of measurement equivalence/invariance. Structural Equation Modeling, II, 60-72. doi:Iо.I207/Si 5328007SEMi Io __5.

Muthén, L.K., \& Muthén, B. (2008). Mplus Version 5.I. Los Angeles, CA: Muthén \& Muthén.

Sarrasin, O., Green, E.G. T., Berchtold, A., \& Davidov, E. (2013). Measurement equivalence across subnational groups: An analysis of the conception of nationhood in Switzerland. International Fournal of Public Opinion Research, 24, 522-534. doi: Io. I093/ijpor/edso33.

Schermelleh-Engel, K., Moosbrugger, H., \& Müller, H. (2003). Evaluating the fit of structural equation models: Tests of significance and descriptive goodness-of-fit measures. Methods of Psychological Research Online, 8, 23-74.

Schiefer, D. (20I3). Cultural values and group-related attitudes: A comparison of individuals with and without migration background across 24 countries. Fournal of Cross-Cultural Psychology, 44, 263-280. doi:Io. I I 77/0022022 I I 2444898.

Selig, J.P., Card, N.A., \& Little, T.D. (2008). Latent variable structural equation modeling in cross-cultural research: Multigroup and multilevel approaches. In F.J. R. Van de Vijver, D.A. Van Hemert \& Y.H. Poortinga (Eds.), Multilevel analysis of individuals and cultures (pp. 93-II9). New York, NY: Laurence Erlbaum.

Steenkamp, J.-B.E. M., \& Baumgartner, H. (I998). Assessing measurement invariance in cross-national consumer research. Journal of Consumer Research, 25, 78-90. doi: I0. I086/209528. 
Steinmetz, H. (20II). Analyzing observed composite differences across groups: Is partial measurement invariance enough? Methodology, 9, I-I2. doi:Io.I027/I6I4224I/a0ooo49.

Swiss Statistical Federal Office. (20I2a). Population mith an immigration background. Retrieved from http://www.bfs.admin.ch/bfs/portal/en/index/themen/or/o7/ blank/key/o4.html.

Swiss Statistical Federal Office. (2012b). Migration and integration-Data, indicators. Retrieved from http://www.bfs.admin.ch/bfs/portal/fr/index/themen/or/o7/ blank/key/or/or.html.

Valentova, M., \& Berzosa, G. (2012). Attitudes toward immigrants in Luxembourg. Do contacts matter? International Reviem of Sociology, 22, 34I-363. doi:Io.1o8o/ 0390670г.2012.696976.

Van de Vijver, F.J. R., \& Leung, K. (I997). Methods and data analysis for cross-cultural research. Thousand Oaks, CA: Sage Publications.

Verkuyten, M., \& Martinovic, B. (20I2). Immigrants' national identification: Meanings, determinants, and consequences. Social Issues and Policy Reviem, 6, 82-II2. doi:Io. I I I /j. I75I-2409.20I I.oI036.X.

Wimmer, A. (2004). Does ethnicity matter? Everyday group formation in three Swiss immigrant neighbourhoods. Ethnic and Racial Studies, 27, I-36. doi:Io.1o8o/ oI 41987032000147922.

\section{Biographical Notes}

Oriane Sarrasin is a postdoctoral research fellow (formerly at the University of Lausanne; now at the University of Sussex with an advanced researcher fellowship from the Swiss National Science Foundation). Her research centers around different forms of group-based discrimination (e.g., sexism and negative attitudes toward immigrants) and the measurement of attitudes.

Eva G. T. Green is senior lecturer at the Institute of Psychology, Faculty of Social and Political Sciences, University of Lausanne, Switzerland. At the crossroads of social and political psychology, she studies the antecedents and consequences of interethnic prejudice and immigration attitudes in contemporary multicultural societies.

Nicole Fasel recently finished her PhD at the Faculty of Social and Political Sciences, University of Lausanne, Switzerland. Her research interests include prejudice related to cultural diversity and age, as well as accessing minorities in social surveys.

Eldad Davidov is Professor of Sociology at the University of Zurich, Switzerland. His research interests are applications of structural equation modeling to survey data, especially in cross-cultural and longitudinal research. Applications include human values, national identity, and attitudes toward immigrants and other minorities. 